\title{
RF Interference Analysis in Aperture Synthesis Interferometric Radiometers: Application to L-Band MIRAS Instrument
}

\author{
Adriano J. Camps, Ignasi Corbella, Member, IEEE, Francesc Torres, Javier Bará, and Joan Capdevila
}

\begin{abstract}
Current spaceborne radiometers do not achieve the required spatial resolution demanded by the scientific community due to antenna-size technological limitations. In recent years, several space agencies have been studying aperture synthesis interferometric radiometers as a way of overcoming these limitations, which are more evident at low microwave frequencies (e.g., at L-band), where sea surface salinity and soil moisture can be monitored. Interference is an important issue in any remote sensing instrument, but it is crucial in microwave radiometers, since the signal being measured is the spontaneous thermal noise emission. Interference analyses already exist for classic radiometers. The objective of this paper is the analysis of RF interference on interferometric radiometers. The study involves the analysis of possible interference sources that may affect the performance of such systems at L-band: 1) nearby emissions from radars, non-Geo-Stationary Orbit (GSO) and Mobile Satellite Services (GSO-MSS), 2) harmonics of lower frequency emissions, and 3) possible jamming.
\end{abstract}

Index Terms-Interference, interferometry, radiometry, remote sensing.

\section{INTRODUCTION}

$\mathbf{T}$ HE basic measurement of an interferometric radiometer (InR) is the so-called visibility function $V_{12}$ in units of Kelvin, obtained from the complex cross-correlation of the signals $b_{1}(t)$ and $b_{2}(t)$, measured by two antennas denoted 1 and 2 [Fig. 1(a)]. Antennas are located above the $X Y$ plane and spaced a normalized distance $\left(u_{12}, v_{12}\right)=\left(x_{2}-x_{1}, y_{2}-\right.$ $\left.y_{1}\right) / \lambda_{0}$, which is called the baseline [1], [2]

$$
\begin{aligned}
V_{12}= & V\left(u_{12}, v_{12}\right) \triangleq \frac{1}{k_{n} \sqrt{B_{1} B_{2}} \sqrt{G_{1} G_{2}}} \cdot \frac{1}{2}\left\langle b_{1}(t) b_{2}^{*}(t)\right\rangle \\
\triangleq & \frac{1}{\sqrt{\Omega_{1} \Omega_{2}}} \iint_{\xi^{2}+\eta^{2} \leq 1} \\
& \cdot \frac{T_{B}(\xi, \eta)}{\sqrt{1-\xi^{2}-\eta^{2}}} F_{n 1}(\xi, \eta) F_{n 2}^{*}(\xi, \eta) \tilde{r}_{12} \\
& \cdot\left(-\frac{u_{12} \xi+v_{12} \eta}{f_{0}}\right) \exp \left(-j 2 \pi\left(u_{12} \xi+v_{12} \eta\right)\right) d \xi d \eta
\end{aligned}
$$

Manuscript received December 18, 1998; revised August 3, 1999. This work was supported by the European Space Agency, Noordwijk, The Netherlands, under Microwave Imaging Radiometer by Aperture Synthesis (MIRAS), Calibration System Definition (CAS-D) European Space and Technology Center (ESTEC) Contract 12513/97/NL/MV).

A. J. Camps, I. Corbella, F. Torres, and J. Bará are with the Polytechnic University of Catalonia (UPC), Barcelona, Spain.

J. Capdevila is with the Microwave Remote Sensing Laboratory, University of Massachusetts, Amherst, MA 01003 USA.

Publisher Item Identifier S 0196-2892(00)02474-8. where $k_{B}$ is the Boltzmann constant $B_{1,2}$ and $G_{1,2}$ are the noise bandwidth and the power gain of the receiving chains [Fig. 1(b)], $\Omega_{1,2}$, and $F_{n 1,2}(\xi, \eta)$ are the equivalent solid angle and the normalized radiation voltage patterns of the antennas, assumed to be located over the $X Y$ plane, and \langle\rangle stands for the time average operator. The directional cosines $(\xi, \eta)=(\sin \theta \cos \phi, \sin \theta \sin \phi)$ are defined with respect to the $X$ and $Y$ axes respectively, and $\tilde{r}_{12}$ is the so-called fringe-wash function, which accounts for spatial decorrelation effects and depends on the normalized frequency response $H_{n 1,2}(f)$ of each channel [1], [2].

The complex cross-correlation of the random analytic signals $b_{1,2}(t)=S_{1,2}(t) e^{j \phi_{1,2}(t)}$ (thermal noise) is normally computed from two real cross-correlations between the in-phase and quadrature components $i_{1,2}(t)$ and $q_{1,2}(t)$

$$
\begin{aligned}
V_{12} & =\left\langle i_{1}(t) i_{2}(t)\right\rangle+j\left\langle i_{1}(t) q_{2}(t)\right\rangle \\
i_{1,2}(t) & =S_{1,2}(t) \cos \left(\phi_{1,2}(t)\right) \\
q_{1,2}(t) & =S_{1,2}(t) \sin \left(\phi_{1,2}(t)\right)
\end{aligned}
$$

When an arbitrary interference $b_{i}(t)=S_{i}(t) e^{j \phi_{i}(t)}$ is present (analytic signal), the complex cross-correlation is given by

$$
\begin{aligned}
V_{12}^{\text {interf }}= & \left\langle\left(i_{1}(t)+i_{i}(t)\right)\left(i_{2}(t)+i_{i}\left(t-t_{d_{i}}\right)\right)\right\rangle \\
& +j\left\langle\left(i_{1}(t)+i_{i}(t)\right)\left(q_{2}(t)+q_{i}\left(t-t_{d_{i}}\right)\right)\right\rangle \\
= & {\left[\left\langle i_{1}(t) i_{2}(t)\right\rangle+\left\langle i_{i}(t) i_{i}\left(t-t_{d_{i}}\right)\right\rangle\right] } \\
& +j\left[\left\langle i_{1}(t) q_{2}(t)\right\rangle+\left\langle i_{i}(t) q_{i}\left(t-t_{d_{i}}\right)\right\rangle\right] \\
= & V_{r 12}+\left\langle i_{i}(t) i_{i}\left(t-t_{d_{i}}\right)\right\rangle \\
& +j\left[V_{i 12}+\left\langle i_{i}(t) q_{i}\left(t-t_{d_{i}}\right)\right\rangle\right] \\
= & V_{r 12}+j V_{i 12}+\left[V_{r}^{\text {interf }}+j V_{j}^{\text {interf }}\right]
\end{aligned}
$$

where $i_{i}(t)=S_{i}(t) \cos \left(\phi_{i}(t)\right), q_{i}(t)=S_{i}(t) \sin \left(\phi_{i}(t)\right)$ are the in-phase and quadrature components of the interfering signal, and $t_{d_{i}}$ is the difference from transit times from the interference source to the antennas, which can be expressed as a function of the location of the interference $\left(\xi_{i}, \eta_{i}\right)$, the baseline, and the center frequency

$$
t_{d_{i}}-\frac{u_{12} \xi_{i}+v_{12} \eta_{i}}{f_{0}}
$$

In order to minimize power consumption and ease the integration of a large number of correlators, an InR (e.g., MIRAS [3]), is being designed to compute $V_{12}$ from the normalized complex 


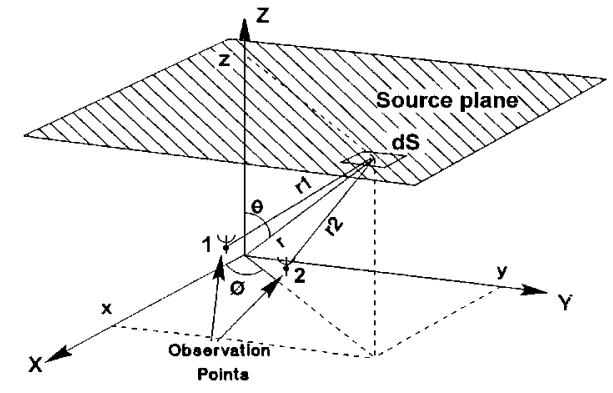

a)

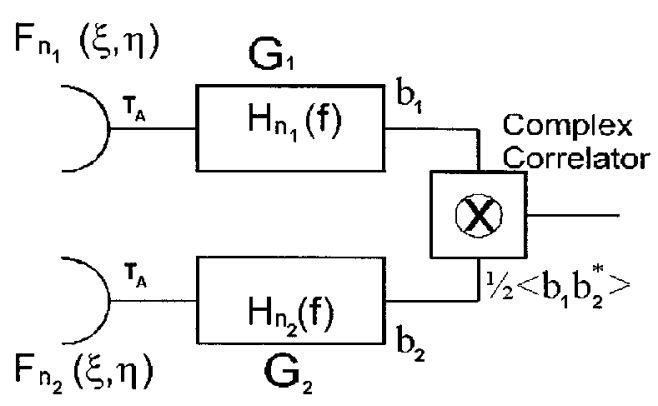

b)

Fig. 1. (a) Two antennas of an interferometric radiometer which form a baseline. (b) Baseline diagram: two receiving chains and a complex correlator.

cross-correlation $\mu_{12}$, measured with $1 \mathrm{bit} / 2$ level $(1 \mathrm{~B} / 2 \mathrm{~L}) \mathrm{dig}-$ ital correlators [4]

$$
\begin{aligned}
Z_{r 12} & =\left\langle\operatorname{sign}\left(i_{1}(t)\right) \operatorname{sign}\left(i_{2}(t)\right)\right\rangle \\
Z_{j 12} & \left.=\left\langle\operatorname{sign}\left(i_{1} 9 t\right)\right) \operatorname{sign}\left(q_{2}(t)\right)\right\rangle \\
\mu_{12} & =\sin \left(\frac{\pi}{2} Z_{r 12}\right)+j \sin \left(\frac{\pi}{2} Z_{j 12}\right) \\
& =\frac{V_{r 12}+j V_{j 12}}{\sqrt{\left(T_{A}+T_{R 1}\right)\left(T_{A}+T_{R 2}\right)}}
\end{aligned}
$$

where $T_{A}$ is the antenna temperature, and $T_{R 1,2}$ are the receiver's noise temperatures of channels 1 and 2 . Since the normalized cross-correlation is computed through the nonlinear function $\operatorname{sign}(x)$, the effect of interference cannot be directly evaluated (3).

\section{RF-INTERFERENCE ANALYSIS}

In the presence of an arbitrary interference signal, the normalized complex cross-correlation $\mu^{\text {interf }} 12$ measured with $1 \mathrm{~B} / 2 \mathrm{~L}$ digital correlators, is given by

$$
\begin{aligned}
& Z_{r 12}^{\text {interf }}=\left\langle\operatorname{sign}\left(i_{1}(t)+i_{i}(t)\right) \operatorname{sign}\left(i_{2}(t)+i_{i}\left(t-t_{d_{i}}\right)\right)\right\rangle \\
& Z_{j 12}^{\text {interf }}=\left\langle\operatorname{sign}\left(i_{1}(t)+i_{i}(t)\right) \operatorname{sign}\left(q_{2}(t)+q_{i}\left(t-t_{d_{i}}\right)\right)\right\rangle \\
& \mu_{12}^{\text {interf }}=\sin \left(\frac{\pi}{2} Z_{r 12}^{\text {interf }}\right)+j \sin \left(\frac{\pi}{2} Z_{j 12}^{\text {interf }}\right) .
\end{aligned}
$$

For arbitrary interfering signals, $b_{i}(t)(6)$ does not admit a closed-form solution, except for a $\mathrm{CW}$ interference. In this case

$$
\begin{aligned}
b_{i}(t) & =A_{i} e^{j \phi_{i}} \\
i_{i}(t) & =A_{i} \cos \left(\phi_{i}\right) \triangleq I \\
q_{i}(t) & =A_{i} \sin (\phi)_{i} \triangleq Q \\
i_{i}\left(t-t_{d_{i}}\right) & =A_{i} \cos \left(\phi_{i}-2 \pi\left(u_{12} \xi+v_{12} \eta\right)\right) \\
& \triangleq A_{i} \cos \left(\phi_{i}+\phi^{\prime}\right)=I \cos \left(\phi^{\prime}\right)-Q \sin \left(\phi^{\prime}\right) \\
q_{i}\left(t-t_{d_{i}}\right) & =A_{i} \sin \left(\phi_{i}-2 \pi\left(u_{12} \xi+v_{12} \eta\right)\right) \\
& \triangleq A_{i} \sin \left(\phi_{i}+\phi^{\prime}\right)=Q \cos \left(\phi^{\prime}\right)+I \sin \left(\phi^{\prime}\right)
\end{aligned}
$$

where $\phi^{\prime}=-2 \pi\left(u_{12} \xi+v_{12} \eta\right)$. The interference [(7b)-(7e)] appears as an offset term added to the in-phase and quadrature components [(6a), (6b)].
Applying Price's Theorem and following a similar procedure to the one described in [5], the normalized, complex cross-correlation can be computed from

$$
\begin{aligned}
Z_{r 12}^{\text {interf }}= & \frac{2}{\pi} \int_{0}^{\mu_{r 12}} \frac{1}{\sqrt{1-s^{2}}} \\
& \cdot \exp \left(-\frac{I^{2}+\left(I \cos \left(\phi^{\prime}\right)-Q \sin \left(\phi^{\prime}\right)\right)^{2}}{2 \sigma^{2}\left(1-s^{2}\right)}\right) d s \\
& +\operatorname{erf}\left(\frac{I}{\sqrt{2} \sigma}\right) \operatorname{erf}\left(\frac{I \cos \left(\phi^{\prime}\right)-Q \sin \left(\phi^{\prime}\right)}{\sqrt{2} \sigma}\right) s \\
Z_{j 12}^{\text {interf }}= & \left.\frac{2}{\pi} \int_{0}^{\mu_{j 12}} \frac{1}{\sqrt{1-s^{2}}}\right) d s \\
& \cdot \exp \left(\begin{array}{c}
\left.-\frac{I^{2}+\left(Q \cos \left(\phi^{\prime}\right)+I \sin \left(\phi^{\prime}\right)\right)^{2}}{2 \sigma^{2}\left(1-s^{2}\right)}\right) \\
\end{array}\right. \\
& +\operatorname{erf}\left(\frac{I}{\sqrt{2} \sigma}\right) \operatorname{erf}\left(\frac{Q \cos \left(\phi^{\prime}\right)+I \sin \left(\phi^{\prime}\right)}{\sqrt{2} \sigma}\right) \cdot
\end{aligned}
$$

If the amplitude of the interference signal is much smaller than that of the thermal noise, which is true in most cases, the main effect is the offset term described in (8). In this case, $\operatorname{erf}(x) \approx 2 x / \sqrt{\pi}$, and the offset term is approximately

$$
\begin{aligned}
Z_{12}^{\text {offset }} & =Z_{r, 12}^{\text {offset }}+j Z_{i, 12}^{\text {offset }} \\
& \approx \frac{2}{\pi} \frac{A_{i}^{2}}{\sigma^{2}} \cos \left(\phi_{i}\right) \exp \left(j \phi_{i}\right) \exp \left(-j 2 \pi\left(u_{12} \xi+v_{12} \eta\right)\right)
\end{aligned}
$$

and

$$
\mu_{12}^{\text {off } f \text { set }} \approx \frac{A_{i}^{2}}{\sigma^{2}} \cos \left(\phi_{i}\right) \exp \left(j \phi_{i}\right) \exp \left(-j 2 \pi\left(u_{12} \xi+v_{12} \eta\right)\right) .
$$

Equation (10) corresponds to the normalized visibility of a point source located at the position of the interference source. From (10), it is clear that the worst case occurs for $\phi_{i}=0^{\circ}$, 


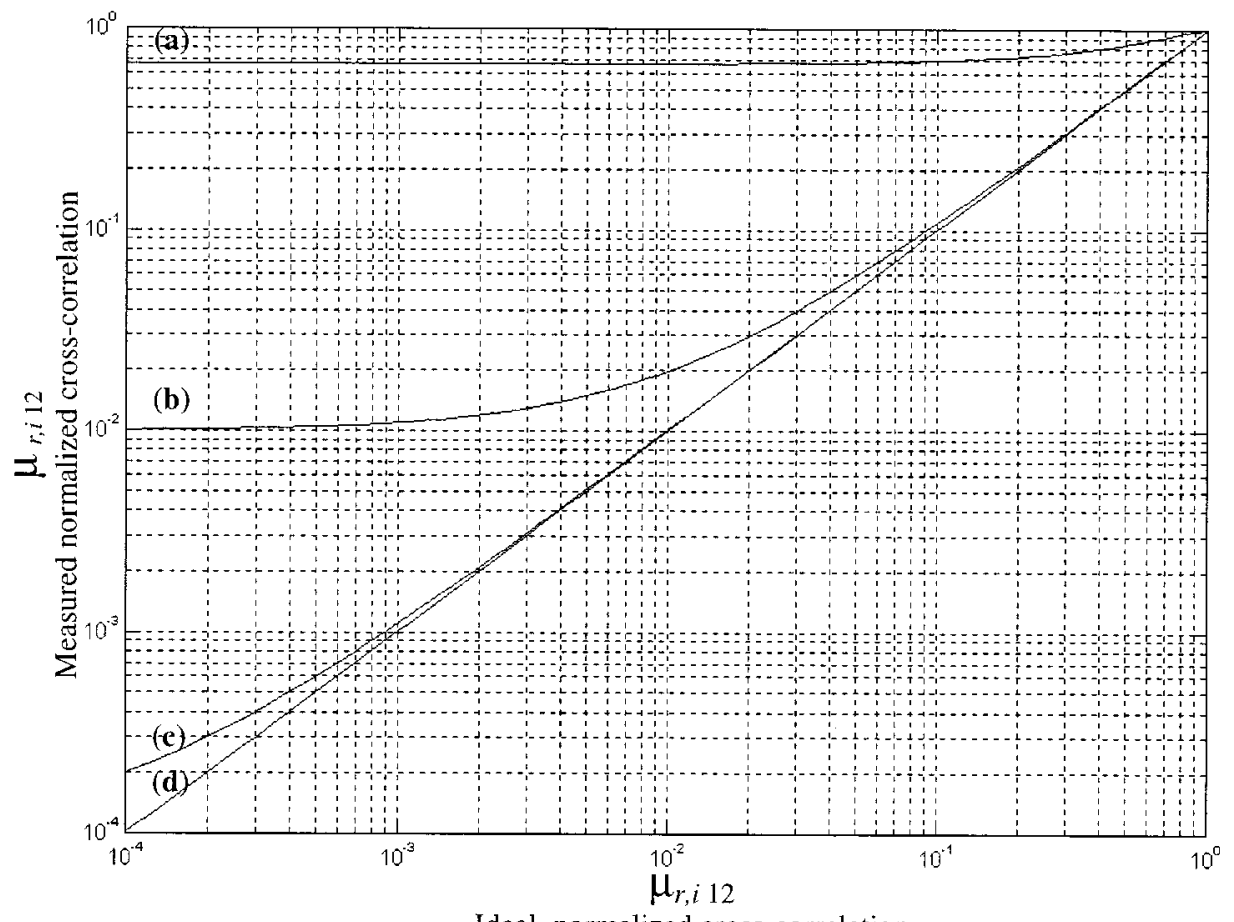

Ideal normalized cross-correlation

Fig. 2. Normalized cross-correlation $\mu_{r 12}^{\prime}$ (for $\phi^{\prime}=0^{\circ}$ ) or $\mu_{i 12}^{\prime}$ (for $\phi^{\prime}=90^{\circ}$ ), under sinusoidal interference versus interference-free normalized cross-correlation $\left(\mu_{r 12}\right.$ or $\left.\mu_{i 12}\right)$ for (a) $20 \cdot \log \left(A_{i} / \sigma\right)=0 \mathrm{~dB}$, (b) $-20 \mathrm{~dB}$, (c) $-40 \mathrm{~dB}$, and (d) $-60 \mathrm{~dB}$.

for which the amplitude of the offset is maximum. In this case, $I=A_{i}, Q=0$ and (8) reduces to

$$
\begin{aligned}
Z_{r 12}^{\text {interf }}= & \frac{2}{\pi} \int_{0}^{\mu_{r 12}} \frac{1}{\sqrt{1-s^{2}}} \\
& \cdot \exp \left(-\frac{A_{i}^{2}+A_{i}^{2} \cos ^{2}\left(\phi^{\prime}\right)-2 A_{i}^{2} \cos \left(\phi^{\prime}\right) s}{2 \sigma^{2}\left(1-s^{2}\right)}\right) d s \\
& +\operatorname{erf}\left(\frac{A_{i}}{\sqrt{2} \sigma}\right) \operatorname{erf}\left(\frac{A_{i} \cos \left(\phi^{\prime}\right)}{\sqrt{2} \sigma}\right) \\
Z_{j 12}^{\text {interf }}= & \left.\frac{2}{\pi} \int_{0}^{\mu_{j 12}} \frac{1}{\sqrt{1-s}}\right) d s \\
& \cdot \exp \left(-\frac{A_{i}^{2}+A_{i}^{2} \sin ^{2}\left(\phi^{\prime}\right)-2 A_{i}^{2} \sin \left(\phi^{\prime}\right) s}{2 \sigma^{2}\left(1-s^{2}\right)}\right) \\
& +\operatorname{erf}\left(\frac{A_{i}}{\sqrt{2} \sigma}\right) \operatorname{erf}\left(\frac{A_{i} \sin \left(\phi^{\prime}\right)}{\sqrt{2} \sigma}\right)
\end{aligned}
$$

which depend on the position of the interference and the baseline $\left(\phi^{\prime}=-2 \pi\left(u_{12} \xi+v_{12} \eta\right)\right)$. In the case of an interference at boresight $\phi^{\prime}=0^{\circ}$, and (11a) reduces to

$$
\begin{aligned}
Z_{r 12}^{\text {interf }}= & \frac{2}{\pi} \int_{0}^{\mu_{r, i 12}} \frac{1}{\sqrt{1-s^{2}}} \exp \left(-\frac{A_{i}^{2}}{\sigma^{2}(1+s)}\right) d s \\
& +\operatorname{erf}^{2}\left(\frac{A_{i}}{\sqrt{2} \sigma}\right) \\
= & \frac{2}{\pi} \arcsin \left(\mu_{r, i 12}\right) \exp \left(-\frac{A_{i}^{2}}{\sigma^{2}} \frac{1}{1+\mu_{r 12}}\right) \\
& +\operatorname{erf}^{2}\left(\frac{A_{i}}{\sqrt{2} \sigma}\right)
\end{aligned}
$$

and so does (11b) for $\phi^{\prime}=90^{\circ}$. The normalized complex visibility can then be obtained from (6c). Fig. 2 plots $\mu_{r 12}$ for $\phi^{\prime}=0$ and for different values of $20 \log \left(A_{i} / \sigma\right)$. Note that the error in the measured normalized visibilities is mainly an offset term (10), whose maximum amplitude is approximately equal to $\left(A_{i} / \sigma\right)^{2}$. Consequently, if the error due to the interference must be lower than $10^{-4}$, and the noise power is about $-100 \mathrm{dBm}$ $\left(\sigma^{2}=k_{B} T_{A} B, T_{A} \approx 150-300 \mathrm{~K}\right)$, the power of the interfering sinusoidal signal must be lower than about $-140 \mathrm{dBm}$.

The effect on the brightness temperature image recovered from (1) is a bright spot in the direction of the interference (10). In the case of other types of interference signals, the effect is more complicated and would require a detailed numerical analysis for the particular type of interfering signal.

\section{APPLICATION TO L-BAND INTERFEROMETRIC RADIOMETERS}

The Electronically Steered Thinned Array Radiometer (ESTAR) and the Microwave Imaging Radiometer by Aperture Synthesis (MIRAS) instruments are L-band one-dimensional (1-D) and two-dimensional (2-D) interferometric radiometers planned for operation in the $1400-1427 \mathrm{MHz}$ band, protected for passive observations [6]. In practice, although there are no transmitters in this band, systems operating at other frequencies may interfere with them. As a first approximation, there are three types of interference sources, listed as follows.

1) Nearby band emissions are high power transmitters whose spurious harmonics are not properly filtered and are radiated in the protected band. The most important ones are L-band radars transmitting high power levels in 


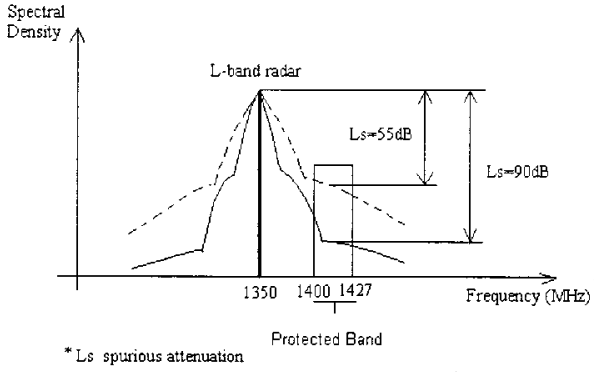

a)

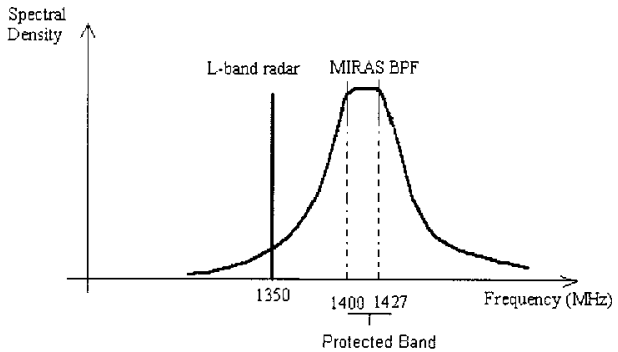

b)

Fig. 3. Situations to be considered in the interference analysis: (a) Interference from spurious falling in the protected band and (b) interference due to radiometers' filters rejection.

the 1200-1400 MHz band. Other systems to be considered are: GSO-MSS (e.g., INMARSAT), non-GSO-MSS (e.g., Iridium), Military Tactical Services, etc.

Two different situations have to be taken into account in the computation of the interfering power lever: a) spurious harmonics falling inside the 1400-1427 MHz band for which the interfering power level set by transmitter's output filter [Fig. 3(a)] and b) spurious collected due to the finite rejection of InR RF filters [Fig. 3(b)].

2) Out of band emissions consist of VHF and UHF systems whose harmonics fall into the 1400-1427 MHz band (e.g. MSS, broadcast satellite services, meteorological satellites, military services, etc).

3) Jamming or deliberate emissions at the $1400-1427 \mathrm{MHz}$ prohibited band may occur, but the authors are not aware of potential sources.

In the next sections, each interference source is analyzed.

\section{A. Nearby Emissions}

1) Interference from L-band radars: Radars transmit high power levels from some hundreds of KW to $10 \mathrm{MW}$. Basically, two types of high power amplifiers (HPA) are used [7].

1) Cross-field amplifiers (CFA's) (e.g., klystrons and magnetrons), generate power levels up to $10 \mathrm{MW}$, but have a "dirty" spectral signature with a $55 \mathrm{~dB}$ spurious frequencies rejection (worst case).

2) Solid state amplifiers (SSA's) generate low power levels (up to $100 \mathrm{KW}$ ) with a clean spectral signature $(90 \mathrm{~dB}$ spurious rejection).

Table I summarizes the performance typical of some L-band radars and their applications.

The average interference power collected by the InR antennas can be computed from

$$
P_{r}=P_{t} \frac{\eta \lambda^{2} G_{t} G_{\operatorname{InR}}}{4 \pi R_{\text {total }}^{2}}\left\{\begin{array}{c}
L_{s} \\
R_{B P F}
\end{array}\right\}\left(L_{\text {reflect }}\right) .
$$

where

$P_{r} \quad$ interference power received at the InR;

$\eta \quad$ duty cycle of pulses transmitted;

$P_{t} \quad$ transmitter's peak powe;

$\eta \quad$ pulse width $\cdot=$ PRF;

lambda wavelength of the interference;

$\begin{array}{ll}\eta & \text { pulse width - = PRF; } \\ G_{t} & \text { transmitter's antenna gain in the emission direc- } \\ & \text { tion of the interference; } \\ G_{\text {InR }} & \begin{array}{l}\text { InR antenna gain in the direction of interference } \\ \text { reception; }\end{array} \\ R_{\text {total }} & \text { total distance between the transmitter and the } \\ & \text { InR (either a direct path or a two-way path } \\ & \text { through a ground reflection); } \\ & \text { antenna gain in the direction of interference re- } \\ & \text { ception; }\end{array}$

In the case of Fig. 3(a) or (b), the attenuation of the spurious frequencies at the transmitter $\left(L_{s}\right)$ or filters selectivity $\left(R_{B P F}\right)$ must be accounted for, as well as the ground reflection coefficient $\left(L_{\text {reflect }}\right)$ in the case of interference through a reflection $\left[\left(L_{s}, R_{B P F}, L_{\text {reflect }}<0 \mathrm{~dB}\right.\right.$ in (13)].

In the evaluation of (13), the parameters of a typical L-band air surveillance radar [8] have been used: $f_{0}=1250-1310$ MHz and 1350-1355 MHz, 3 ms pulse width, $365 \mathrm{~Hz}$ PRF, peak power 1.8 MW, antenna gain $36.5 \mathrm{~dB}$ (maximum at an elevation of $5^{\circ}$ ), and spurious attenuation $L_{s}=-55 \mathrm{~dB}$ (worst case). The main parameters of the InR are the ones corresponding to the MIRAS demonstrator instrument, as listed in Table II.

a) Radar spurious frequencies in the 1400-1427 $\mathrm{MHz}$ band: Equation (13) needs to be evaluated for different relative positions of the ground radar and the InR [Fig. 4(a)]. The InR boresight direction corresponds to $(0,0)$, the radar is located at each coordinate, and its antenna pattern is pointing to $+\hat{y}$. Results are presented in Fig. 4(b). As expected, due to the shape of the radar antenna pattern, locations along the MIRAS ground track cause the largest interference. The boresight direction is plotted using a small circle at $(0,0)$. The error regions $e=10^{-4}$, $(P r \approx-140 \mathrm{dBm})$ and $e=10^{-2}(P r \approx-120 \mathrm{dBm})$ are represented by two solid lines. From Fig. 4(b), the following can be concluded.

1) Since the radar antenna beamwidth is usually much larger in the vertical plane than in the horizontal one, the area where the interference is maximum is along the InR ground-track [y-axis, Fig. 4(b)].

2) Due to the wide pattern of the InR antennas, the interfering radar creates the largest interference when it points at the InR (elevation angle of $5^{\circ}$ ).

3) The maximum interference occurs when the radar is located $1500 \mathrm{Km}$ away from the boresight direction. In this 
TABLE I

POSSIBLE INTERFERENCES FROM NEAR-BAND EMISSIONS AND HARMONICS. $H^{*}$ HARMONIC NUMBER (IF ANY)

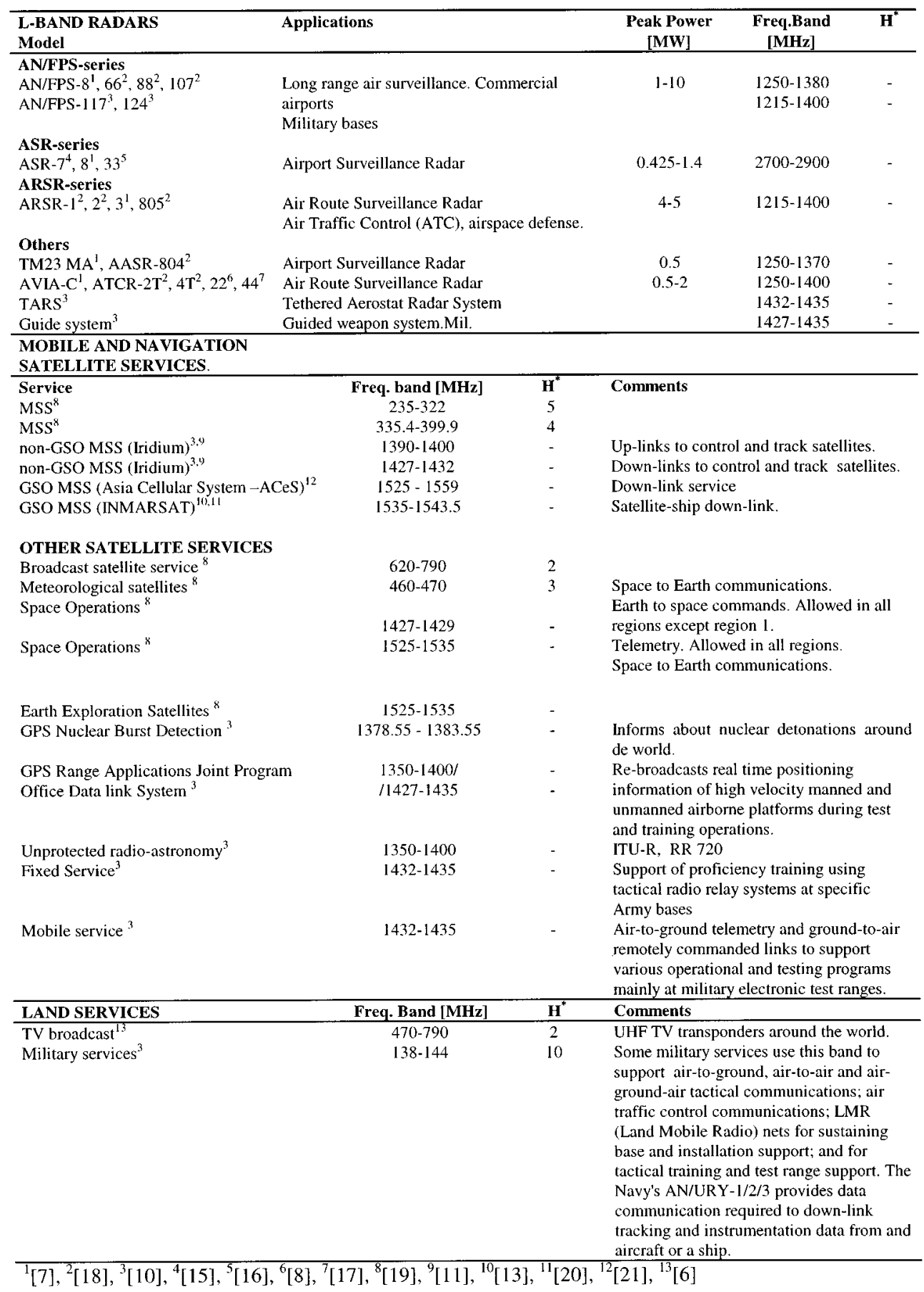

TABLE II

MIRAS DEMONSTRATOR PARAMETERS [22]

\begin{tabular}{ll}
\hline Orbital height & $672 \mathrm{~km}$ \\
Tilt angle & $49.37^{\circ}$ \\
Antenna gain & $9 \mathrm{~dB}$ \\
Half power beamwidth & $60^{\circ}$ \\
\hline
\end{tabular}

situation, the induced error is larger than $10^{-4}$ when it is located at distances smaller than $70 \mathrm{Km}$ from the $\mathrm{InR}$ ground-track.
4) If the spurious rejection is $L_{s}=-90 \mathrm{~dB}$ (instead of $L_{s}=-55 \mathrm{~dB}$ ), the interfering power level is always smaller than $-145 \mathrm{dBm}$ for any radar location, and the induced error is negligible.

b) Interference due to filters' finite rejection: InR RF filters are responsible for rejecting the power from out-of-band emissions. These filters are designed to have high selectivity. The specifications for the MIRAS demonstrator instrument are summarized in Table III [9]. In addition to the filters' selectivity, the insertion loss introduced by the antennas' out-of-band mismatch must be considered. The evaluation of (11) for the 


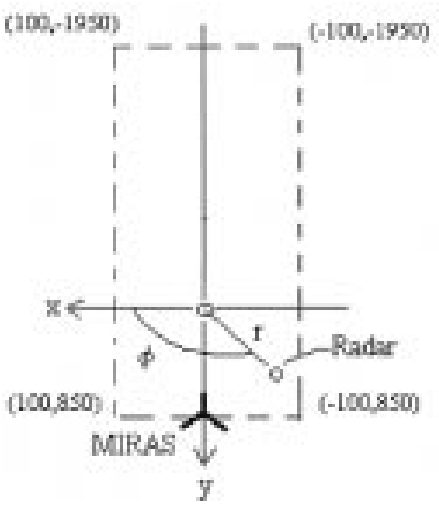

a)

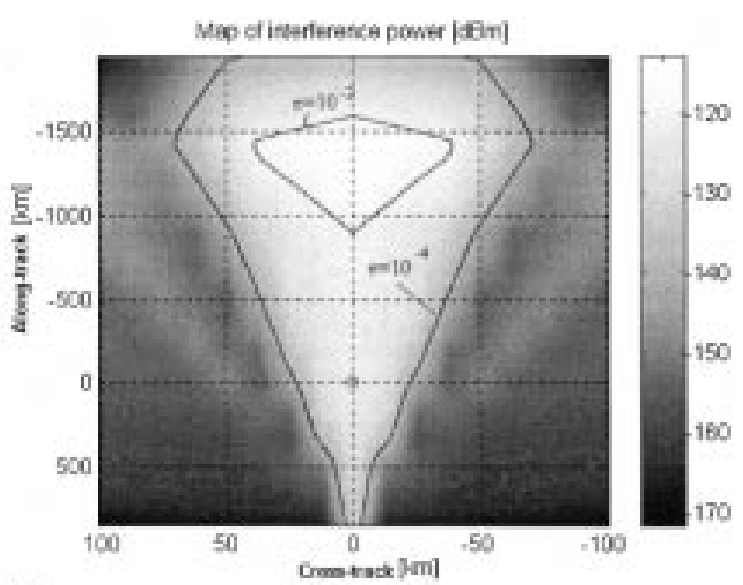

b)

Fig. 4. (a) Geometric description of the problem (top view) and (b) map of interference power level.

TABLE III

SPECIFICATIONS OF MIRAS BAND PASS FILTER [9]

\begin{tabular}{lll}
\hline Parameter & Specification & Unit \\
\hline $1404-1423 \mathrm{MHz}$ Ripple (3dB att.) & 0.2 & $\mathrm{dBpp}$ \\
$1400-1427 \mathrm{MHz}$ Rejection & $>25$ & $\mathrm{~dB}$ \\
$1395-1432 \mathrm{MHz}$ Rejection & $>40$ & $\mathrm{~dB}$ \\
$1380-1450 \mathrm{MHz}$ Rejection & $>80$ & $\mathrm{~dB}$ \\
$1200-1600 \mathrm{MHz}$ Rejection & $>100$ & $\mathrm{~dB}$ \\
$10-95000 \mathrm{MHz}$ Rejection & (non-defined) & $\mathrm{dB}$ \\
\hline
\end{tabular}

AN/FPS-8 radar $f_{i}=1380 \mathrm{MHz}, P_{t}=1 \mathrm{MW}$, and $R_{B P F}=$ $-80 \mathrm{~dB}$ shows that the interference power level is always smaller than $-142 \mathrm{dBm}$, thus introducing a negligible error.

2) Interference from Nongeostationary Orbit Mobile Satellite Services (MSS's): Several institutions and companies have asked ITU-R for permission to use the bands adjacent to the 1400-1427 $\mathrm{MHz}$ band for new fixed and mobile commercial and consumer communication applications [10]. The proposed usage of these bands is

1) 1390-1400 MHz: Earth-to-space links;

2) 1427-1432 MHz: Space-to-earth links for non-GSO MSS systems with service links operation below $1 \mathrm{GHz}$.

One of the most important matters of these new services is their potential interference on the band 1400-1427 MHz protected for passive observations. Some studies have been carried out to assess the compatibility between the proposed services and this protected band [11]. The possible interference of uplinks and downlinks is studied in this section.

a) Feeder uplinks (earth-to-space) in the 1390-1393 $\mathrm{MHz}$ band: The purpose of the Ground Stations (GS) network is to track the MSS constellation. Typical GS parameters are [11]: $P_{t}=10 \mathrm{~W}, 30 \mathrm{~dB}$ antenna gain, and, since the spurious frequencies are so close to the carrier, their rejection is estimated to be $L_{s} \approx-30 \mathrm{~dB}$.

Among the large number of possible relative orientations between the GS and the InR platform, the worst case occurs whenever the GS antenna and the InR antennas are pointing at each
TABLE IV

PARAMETERS OF A AN/FPS-24 P-BAND RADAR

\begin{tabular}{ll}
\hline Model & AN/FPS-24 \\
\hline Frequency Band & $214-236 \mathrm{MHz}$ \\
Pulse Width & $6.18 \mu \mathrm{s}$ \\
PRF & $278 \mathrm{~Hz}$ \\
Peak Power $\left(P_{t}\right)$ & $5 \mathrm{MW}$ \\
$6^{\text {th }}$ harmonic rejection $L_{s}$ & $\sim-100 \mathrm{~dB}$ \\
Antenna gain & $30 \mathrm{~dB}$ \\
\hline
\end{tabular}

other, which corresponds to an elevation of the GS antenna beam of $33^{\circ}$. In this case, the interfering power level is $P_{r} \approx-107$ $\mathrm{dBm}$, which is much larger than the $10^{-1}$ error threshold. Of course, this result relies on the assumption $L_{s}=-30 \mathrm{~dB}$ and has to be taken conservatively, since better values are expected to apply for GS. Assuming that the Blackmann window is used to taper the visibility samples, the side lobes of the equivalent array factor (or impulse response [24]) at $-16.5 \mathrm{~dB},-18.4 \mathrm{~dB}$, and $-19.8 \mathrm{~dB}$ appear at $2.61^{\circ}, 3.42^{\circ}$, and $4.92^{\circ}$ from boresight. In the first and last cases, the region around the interference is about $92 \mathrm{~km} \times 50 \mathrm{~km}$, and $175 \mathrm{~km} \times 95 \mathrm{~km}$, respectively, for which the errors will be 0.004 and 0.002 . Although this accuracy is enough for some land applications, the induced error may be severe for the recovery of sea surface salinity, for which an absolute accuracy well below $1 \mathrm{~K}$ is required.

b) Feeder downlinks (space-to-Earth) in the 1429-1432 $\mathrm{MHz}$ band: Two possible scenarios have to be analyzed when calculating possible interference from down-link feeders: direct interference and interference from power scattered over the Earth's surface.

The parameters of non-GSO MSS satellites needed in (13) are [11]: polar orbit height $765.37 \mathrm{Km}$, antenna gain $-9 \mathrm{~dB}$ at $\theta=0^{\circ}$ (boresight), and $+2.5 \mathrm{~dB}$ at $\theta=60^{\circ}$, transmitted power $P_{t}=1 \mathrm{~W}$, and spurious attenuation $L_{s}=-30 \mathrm{~dB}$.

In the case of direct interference, the maximum interference power occurs when the antenna of the non-GSO satellite is pointing at the InR, and the non-GSO is over the InR. Even 
TABLE V

SUMMARY OF MAJOR INTERFERING SOURCES

\begin{tabular}{|c|c|c|c|}
\hline \multirow[t]{2}{*}{ System } & \multirow[t]{2}{*}{ Typical $P_{r}$ at InR Antenna } & \multicolumn{2}{|c|}{ Correlation error } \\
\hline & & $\mathrm{e} \geq 10^{-4}$ & e $\geq 10^{-2}$ \\
\hline L-band radars & $-110 \mathrm{dBm}$ & YES & YES \\
\hline GSO MSS (satellite-ship link) & & & \\
\hline Direct interference & $-155 \mathrm{dBm}$ & No & No \\
\hline Interference from scattering & $-150 \mathrm{dBm}$ & No & No \\
\hline non-GSO MSS & & & \\
\hline Up-link & $-110 \mathrm{dBm}$ & $(*)$ & $\left(^{*}\right)$ \\
\hline Down-link: & $-145 \mathrm{dBm}$ & No & No \\
\hline Direct interference & $-150 \mathrm{dBm}$ & No & No \\
\hline Interference from scattering & & & \\
\hline TV transponders & $-155 \mathrm{dBm}$ & No & No \\
\hline P-band radars & $-155 \mathrm{dBm}$ & No & No \\
\hline
\end{tabular}

${ }^{(*)}$ Negligible for $L_{s} \leq-60 \mathrm{~dB}$, Important for spurious rejection $L_{s}=-30 \mathrm{~dB}$

given the close distance between both satellites, the InR antenna pattern attenuates so highly that the interference power level reaching the InR platform through direct path $\left(P_{r} \leq-147\right.$ $\mathrm{dBm})$ can always be neglected.

In the case of scattering over the Earth's surface, the interference lies within the InR antenna's main beam, but the larger path attenuation reduces the interfering power level to a negligible value $\left(P_{r} \leq-152 \mathrm{dBm}\right)$.

3) Interference from GSO sytems: The primary mission of the INMARSAT system is to provide a communication service to ships and maritime platforms using three Geo-Stationary Orbit (GSO) satellites over the three main ocean regions, with global beam coverage in each zone [12], [13]. Several links must be considered.

1) satellite-to-ship downlink (1535-1543.5 MHz) and ship-to-satellite uplink (1636.5-1645 MHz);

2) satellite-to-shore stations downlink (4195-4199 MHz) and shore stations-to-satellite up-link (6420-6424 MHz). This communication provides the link from the MSS network to the Public Switched Telephone Network (PSTN) and the Public Land Mobile Network (PLMN).

The frequency band most likely to generate interference, is the satellite-to-ship downlink because of its proximity to the $1400-1427 \mathrm{MHz}$ band. As in the case of non-GSO Satellites, direct interferences and interferences from scattering over the Earth's surface are possible. However, for INMARSAT's EIRP $=39 \mathrm{dBW}$, assuming a spurious rejection of $L_{s}=-40 \mathrm{~dB}$ (worst case) and filter specifications of the MIRAS demonstrator (Table III), neither direct interference nor interference from scattering nor interference due to InR RF filters' selectivity would produce an interference power level larger than $-150 \mathrm{dBm}$.

4) Harmonics from Lower Frequency Emissions: Systems operating in lower frequency bands may interfere within an L-band InR through the emission of harmonics. Since there are many types of VHF/UHF transmitters, our analysis has focused on two high power sources: terrestrial TV transponders and P-band radars. The level of harmonics with respect to the carrier depends on the selectivity of the transmitter's filter, the linearity of the high power amplifiers, etc.

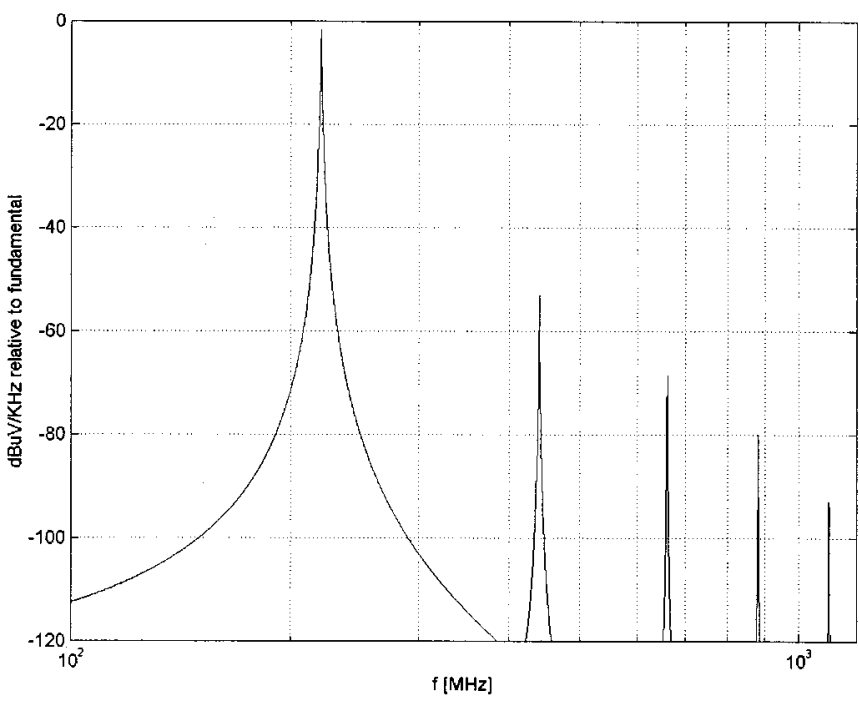

Fig. 5. Typical spectral signature of a P-band long-range search radar [23].

a) Terrestrial UHF TV-transponders: The UHF band is basically devoted to the broadcasting of TV signals over a local area. Typical parameters of TV transponders are [14]: maximum transmitted power $10 \mathrm{~W}$, spurious rejection better than $60 \mathrm{~dB}$, and $13 \mathrm{~dB}$ antenna gain. The maximum interfering power (TV transponder pointing directly to the InR antennas at an elevation angle of $5^{\circ}$ ) can then be estimated to be smaller than $-154 \mathrm{dBm}$ (11), which is completely negligible.

b) P-band radars: P-band radars are long-range search systems operating at VHF. Their major characteristics are their high output power and high harmonic emissions (Fig. 5). Table IV summarizes the parameters of a typical P-band radar. The interference power level is then estimated to be smaller than -155 $\mathrm{dBm}$, which again, is completely negligible for InR operation.

\section{CONCLUSIONS}

In the first part of this paper, the effect of RF interference on the performance of interferometric radiometers has been studied theoretically. The study has been applied to the analysis of a sinusoidal interference and an InR using 1 bit/2 level digital correlators, which are planned for the MIRAS demonstrator instrument, due to their lower power consumption and ease of inte- 
gration. It has been shown that, as it is common for low correlation values and interference power levels, smaller than the noise background, the main effect is an offset term added to the estimated correlation. The amplitude of the offset is proportional to the interfering power level, and its phase corresponds to interference pixel locations.

In the second part, possible interference sources at L-band have been analyzed and evaluated for typical systems: 1) nearby emissions from L-band radars, non-GSO and GSO MSS, 2) harmonics of lower frequency emissions, and 3) possible jamming, which may or may not be deliberately generated. Table V summarizes the worst case values of the interference power levels for typical systems. Note that, since the interfering power levels are always within the dynamic range of the receivers, they are not expected to saturate the front-end and produce only a bright pixel at the interference location. From all the possible interferences, the most important ones are generated by L-band radars due to the high levels of transmitted power, which may interfere in an area of $80 \mathrm{~km} \times 700 \mathrm{~km}$ (error $>10^{-2}$ ) and non-GSO MSS up-link transmitters (due to the low spurious rejection and to their proximity to the $1400-1427 \mathrm{MHz}$ band), which may interfere in an area of $50 \mathrm{Km} \times 92 \mathrm{Km}\left(\right.$ error $\left.>10^{-2}\right)$.

\section{REFERENCES}

[1] A. R. Thompson, J. M. Moran, and G. W. Swenson, Interferometry and Synthesis in Radio Astronomy. New York: Wiley, 1986.

[2] C. S. Ruf, C. T. Swift, A. B. Tanner, and D M. LeVine, "Interferometric synthetic aperture radiometry for the remote sensing of the earth," IEEE Trans. Geosci. Remote Sensing, vol. 26, pp. 597-611, Sept. 1988.

[3] M. Martín-Neira and J. M. Goutoule, "MIRAS-A two-dimensional aperture-synthesis radiometer for soil-moisture and ocean salinity observations," ESA Bull., no. 92, pp. 95-104, Nov. 1997.

[4] J. B. Hagen and D. T. Farley, "Digital-correlation techniques in radio science," Radio Sci., vol. 8, pp. 775-784, Aug./Sept. 1973.

[5] A. Camps, F. Torres, I. Corbella, J. Bará, and J. A. Lluch, "Threshold and timing errors of $1 \mathrm{bit} / 2$ level digital correlators in earth observation synthetic aperture radiometry," in Electron. Lett., vol. 33, Apr. 24, 1997, pp. 821-813.

[6] ITU Radio Regulations, Frequency Allocation National Bulletin, Official Bull. Span State, Aug. 9, 1996.

[7] M. I. Skolnik, Radar Applications. New York: IEEE Press, 1988.

[8] Manual of the ATCR-22, ATCR 22 L Band Air Traffic Control Surveillance Radar.", Civil Radar and Systems Division, Industrie Eletroniche Associate S.p.A., 1980.

[9] MIRAS Programme Licef Doc. TNO/MIRA/LICF-0022, Mier Comunicaciones S.A., 1998, p. 56.

[10] Spectrum Reallocation Report: Response to Title III of the Balance Budged Act of 1997," NTIA Special Pub. 97-036., Office of Spectrum Management, National Telecommunications and Information Administration (NTIA).

[11] R. Crenshaw, "Compatibility analysis between non-geostationary mobile satellite services (non-GSO MSS) feeder-links and the existing services near 1.4 GHz," Eur. Space Agency Rep., Jan. 1998.

[12] G. Maral, Satellite Communications Systems. New York: Wiley, 1987.

[13] W. L. Pritchard, Satellite Communications Systems Engineering, 2nd ed.. Englewood Cliffs, NJ: Prentice Hall, 1993.

[14] Professional TV Transpoders, Commercial Catalogue: Mier Communicaciones S.A., 1993.

[15] Operation and maintenance instructions for airport surveillance radar model ASR-7 (AN/GPN-12), T.O.P5-2GPN12-2, DOT, 1995.

[16] Manual of the ATCR $33 S$ band air traffic control terminal area radar. Selenia, Industrie Elettroniche Associate S.p.A. Civil Radar and Systems Division, GPB 77/16 Rev. 1/80.

[17] ATCR 44 L band air traffic control surveillance radar, Selenia, Industrie Elettroniche Associate S.p.A. Civil Radar and Systems Division, GPB 8/04 Rev. 1/82.

[18] E. Brookner, Radar Technology. Dedham, MA: Artech House, 1977 , ch. 1.
[19] W. L. Morgan, Communications Satellite Handbook, 1989.

[20] R. G. Gould, Communications Satellite Systems: An Overview of the Technology. New York: IEEE Press, 1975.

[21] B. Miller, "Satellites free the mobile phone," IEEE Spectrum, vol. 35, pp. 26-35, Mar. 1998.

[22] The MIRAS demonstrator. Annex 1, European Space and Technology Center (ESTEC), int. doc., 1998

[23] D. White, A Handbook Series on Electromagnetic Interference and Compatibility, 3rd ed.. Gainesville, FL: Don White Consultants, 1981, vol. Section 2.3 .

[24] J. Bará, A. Camps, F. Torres, and I. Corbella, "Angular resolution of twodimensional hexagonally sampled interferometric radiometers," Radio Sci., vol. 33, pp. 1459-1473, Sept./Oct. 1998.

Adriano J. Camps received the Ing. and Dr. Ing. in telecommunications from the Polytechnic University of Catalonia (UPC), Barcelona, Spain in 1992 and 1996, respectively.

In 1991-1992, he received an Erasmus Fellowship to study at the ENS des Télécommunications de Bretagne, France. In 1993, he joined the Electromagnetics and Photonics Engineering Group, Department of Signal Theory and Communications, UPC, as an Assistant Professor, and has been an Associate Professor since 1997. Since 1999, he has been on sabbatical at the Microwave Remote Sensing Laboratory, University of Massachusetts, Amherst, as a Visiting Professor. His research interests are focused on passive and active microwave remote sensing, particularly the MIRAS instrument, currently approved by the European Space Agency as an Earth Explorer Mission under the name of SMOS.

Dr. Camps received the second Spanish National Prize of University Studies in 1993, and in 1997, he received the INDRA award for the best Ph.D. in remote sensing. He is Member of the Spanish Association of Telecommunication Engineers.

Ignasi Corbella (M'98) was born in Barcelona, Spain, in 1955. He received the Ing. and Doctor Ing. degrees in telecommunication engineering, both from the Universitat Politècnica de Catalunya (UPC), Barcelona, Spain, in 1977 and 1983, respectively.

In 1976, he joined the School of Telecommunication Engineering, Barcelona as a Research Assistant in the Microwave Laboratory, where he worked on passive microwave integrated circuit design and characterization. He became Assistant Professor in 1982, Associate Professor in 1986, and Professor in 1993. $\mathrm{He}$ is currently teaching microwaves at the undergraduate level in the same institution. From 1998 to 1999, he worked at NOAA/Environmental Technology Laboratory, Boulder, CO, as a Guest Researcher, developing methods for radiometer calibration and data analysis. His research work in the Department of Signal Theory and Communications with UPC includes microwave airborne and satellite radiometry and microwave system design.

Francesc Torres was born in Ibiza, Spain, in 1962. He received the Dr. Ing. degree in telecommunication engineering, both from the Polytechnic University of Catalonia (UPC), Barcelona, Spain, in 1988 and 1992, respectively.

From 1988 to 1989, he was a Research Assistant in the RF System Division, European Space Agency, Noordwijk, The Netherlands, where he worked on microwave device testing and characterization. In 1989, he joined the Antenna-Microwave-Radar group of the UPC, where he is currently a Professor. His main research interests are focused on the design and testing of microwave systems and subsystems. He is currently engaged in research on interferometric radiometers devoted to Earth observation.

Javier Bará was born on September 30, 1944. He received the Sc.M. degree in 1968 and the Ph.D. degree in 1972, both in electrical engineering, from Brown University, Providence, RI.

Since 1972, he has been a Professor with the Polytechnic University of Catalonia (UPC), Barcelona, Spain, where he held several posts of academic responsibility as Associate School Dean, Dean, and Department Director.

His research interests have been in the field of microwaves (ferrites, integrated circuits, satellite communications, industrial heating, and drying processes), and at present, he is involved in projects in nonguided optical communications in the near-infrared and interferometric radiometry for remote sensing of the Earth. 
Joan Capdevila was born in L'Albi, Spain, in 1974. He received the Ing. degree in telecommunications engineering from the Universitat Politècnica de Catalunya (UPC), Barcelona, Spain, in 1998. His final project was focused on the implementation of a Dicke radiometer and the measurement of the four Stokes parameters of rain events.

In January 1999, he joined the Microwave Remote Sensing Laboratory, University of Massachusetts, Amherst, as a Research Assistant. His thesis is focused on the design and implementation of a dual beam along-track interferometric SAR for ocean current mapping applications. 